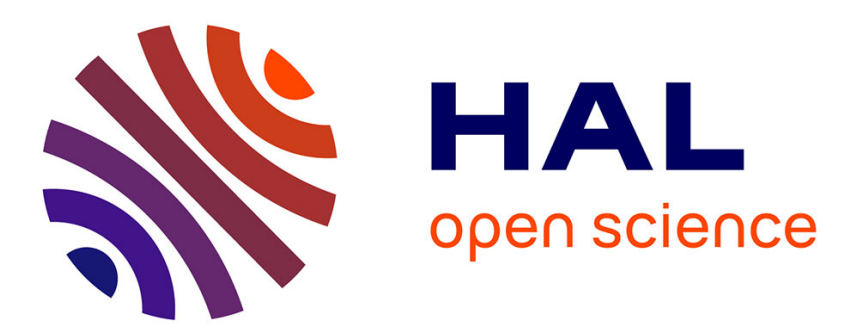

\title{
Experimental analysis of the influence of tensions on in plane shear behaviour of woven composite reinforcements
}

\author{
Jean Launay, Gilles Hivet, Ahn V. Duong, Philippe Boisse
}

\section{To cite this version:}

Jean Launay, Gilles Hivet, Ahn V. Duong, Philippe Boisse. Experimental analysis of the influence of tensions on in plane shear behaviour of woven composite reinforcements. Composites Science and Technology, 2007, 68 (2), pp.506. 10.1016/j.compscitech.2007.06.021 . hal-00498991

\section{HAL Id: hal-00498991 https://hal.science/hal-00498991}

Submitted on 9 Jul 2010

HAL is a multi-disciplinary open access archive for the deposit and dissemination of scientific research documents, whether they are published or not. The documents may come from teaching and research institutions in France or abroad, or from public or private research centers.
L'archive ouverte pluridisciplinaire HAL, est destinée au dépôt et à la diffusion de documents scientifiques de niveau recherche, publiés ou non, émanant des établissements d'enseignement et de recherche français ou étrangers, des laboratoires publics ou privés. 


\section{Accepted Manuscript}

Experimental analysis of the influence of tensions on in plane shear behaviour of woven composite reinforcements

Jean Launay, Gilles Hivet, Ahn V. Duong, Philippe Boisse

PII: S0266-3538(07)00251-5

DOI: 10.1016/j.compscitech.2007.06.021

Reference: CSTE 3742

To appear in: Composites Science and Technology

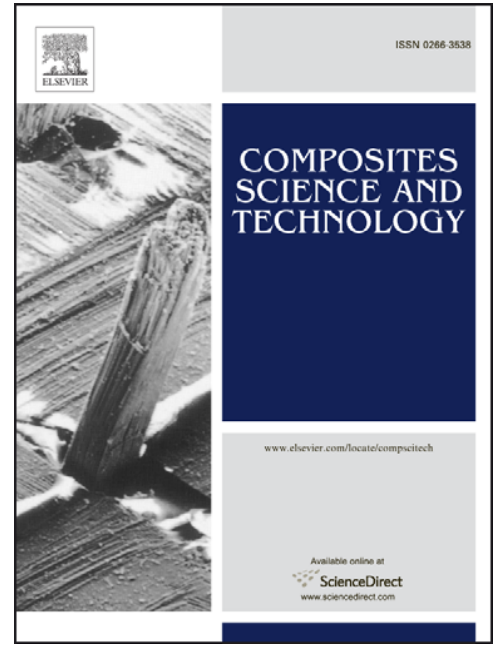

Received Date: $\quad 5$ December 2006

Revised Date: $\quad 19$ March 2007

Accepted Date: $\quad 6$ June 2007

Please cite this article as: Launay, J., Hivet, G., Duong, A.V., Boisse, P., Experimental analysis of the influence of tensions on in plane shear behaviour of woven composite reinforcements, Composites Science and Technology (2007), doi: 10.1016/j.compscitech.2007.06.021

This is a PDF file of an unedited manuscript that has been accepted for publication. As a service to our customers we are providing this early version of the manuscript. The manuscript will undergo copyediting, typesetting, and review of the resulting proof before it is published in its final form. Please note that during the production process errors may be discovered which could affect the content, and all legal disclaimers that apply to the journal pertain. 


\title{
Experimental analysis of the influence of tensions on in plane shear behaviour of woven composite reinforcements
}

\author{
Jean Launay $^{\mathrm{a}}$, Gilles Hivet ${ }^{\mathrm{a}}$, Ahn V. Duong ${ }^{\mathrm{a}}$, Philippe Boisse ${ }^{\mathrm{b} *}$ \\ ${ }^{a}$ Laboratoire de Mécanique des Systèmes et des Procédés, \\ Polytech Orléans, ENSAM Paris, France \\ ${ }^{b}$ Laboratoire de Mécanique des Contacts et des Solides \\ INSA de Lyon, France
}

\begin{abstract}
In plan shear behaviour of textile performs is the most studied mechanical property because this mode of deformation is necessary for forming on double-curvature surfaces. In the large majority of experimental and simulation analyses, it is assumed that the shear behaviour does not depend on the tensions in the yarns. In particular the picture frame shear test supposes that the yarn tensions are equal to zero or without consequence. In this article, an experimental device is proposed which enables to measure the tensions during a picture frame test. It is shown that initial tensions modify the response in shearing, particularly in the first part of the shear curve. Furthermore it is also shown that the tension during a picture frame test without initial tension does not remain equal to zero. Finally when slackening the tension to zero during a picture frame test, the measured shear force noticeably decreases and reaches values close to those obtained by a bias test.
\end{abstract}

Keywords : A. Fabrics/Textiles; A. Textile composites; B. Mechanical properties; B. Non-linear behaviour; In plane shear behaviour

* Corresponding author. Tel.: +33 4724363 96; Fax : +334 72438525

E-mail address: philippe.boisse@insa-lyon.fr (P. Boisse). 


\section{1 - Introduction}

Virtual manufacture of industrial components can provide significant increase in efficiency in manufacturing process development. In this goal, composite industry supports the development of simulation codes for composite forming processes [1-4]. Among these, draping simulation i.e. simulation of the forming of continuous textile preforms takes an important part. These textile preforms present advantages such as ability to drape over complex double curvature surfaces. They are used in LCM (Liquid Composite Moulding) technologies. In case of double curvature, the textile perform is generally woven to permit in plane strain necessary for forming without dissociation of the fibres. In addition woven textile composite are damage tolerant due to resistance offered by interlacing tows to crack propagation. For woven reinforcement draping simulation, a first family of codes have been developed based on the so-called fishnet algorithm [5][1][6]. Advantages of this approach (called 'kinematic' modelling) are simplicity and speed computation making it suitable for commercialisation. Nevertheless these methods have major drawbacks. They do not take the mechanical behaviour of the fabric and the static boundary conditions into account. The alternative to these kinematic methods consist in a mechanical analysis of the fabric deformation under the boundary conditions prescribed by the forming process. This needs a model of the mechanical behaviour of the woven reinforcement and usually a numerical method, within, for instance, the finite element method [2][7-12][4]. Consequently it is necessary to perform sufficient experimental analyses to provide the necessary information on the mechanical behaviour of textile reinforcements during forming. These deformations are complex. Textile preforms undergo biaxial tensile deformation, in-plane shear deformation, transverse compaction and out-of-plane bending deformations. If all these deformation can be significant in some cases, it is generally possible to use a simplified approach where only some strain energies are taken into account. For instance in section 2, the strain energy takes only biaxial tensile and in plane shear energy into account. 
The in plane shear strain are necessary for woven reinforcement forming on a double curvature surface. The shear angles can be very large (up to $50^{\circ}$ ) while the tensile strains remain small (1.5\% for a carbon fabric). The in plane shear behaviour of woven fabrics has been much studied [13-24], much more than the other elementary mechanical behaviours. Two tests are mainly used. The "picture frame" which uses a lozenge framework made of four rigid and articulated bars and the "bias test" which is a tensile test on a sample with initially a $45^{\circ}$ angle between the yarns and the edges. A benchmark carried out by different laboratories on identical woven composite fabrics led to large discrepancy between the results especially for those obtained via the picture frame test [21]. This tends to show that this test is not completely controlled. In $[25,26]$ the mechanical behaviour of woven fabric is modelled from the internal geometry of a unit woven cell and from the yarn mechanical properties. This model clearly shows in [26] that the shear behaviour depends on the tension. Nevertheless in the different approaches used for simulations of fabric forming the shear behaviour is supposed not to depend on the tensions in the yarns. This is called into question in this paper. In that goal, an experimental device making it possible to measure the tensions during the test is carried out. Thanks to this device, it is shown that tensions play a role in plane shear behaviour. It is also shown that if initial tensions are set to zero, the tensions in the yarns during a picture frame test does not remain null. Finally the relaxation to zero of the tensions during the test leads to measured shear force noticeably reduced and that reach values close to those obtained by a bias test.

\section{2 - Mechanical behaviour of woven composite reinforcements}

The woven reinforcements used in composites are composed of yarns or tows made up themselves of thousands of small carbon, glass, aramid... fibres. The warp and weft yarns are joined by weaving. The mechanical behaviour which results is complex and specific considering the possibilities of relative movements between yarns and fibres. All rigidities of such a woven reinforcement are low compared to those of tension in the warp and weft directions. A mechanical 
behaviour model must take this specificity into account and be as simple as possible. It must also convey :

- non-linearities of behavior due to the undulations of the yarns

- the increase in shear rigidity with the angle between warp and weft yarns especially when this shear angle becomes large.

In the approach presented in [11,27], only tensile strain energy and in plane shear strain energy are taken into account. A simplified form of the virtual internal load work on a set of ncell woven unit cells is considered :.

$$
\mathrm{W}_{\text {int }}(\underline{\eta})=\sum_{\mathrm{p}=1}^{\text {ncell }}\left({ }^{\mathrm{p}} \varepsilon_{11}(\underline{\eta}){ }^{\mathrm{p}} \mathrm{T}^{11 \mathrm{p}} \mathrm{L}_{1}+{ }^{\mathrm{p}} \varepsilon_{22}(\underline{\eta}){ }^{\mathrm{p}} \mathrm{T}^{22 \mathrm{p}} \mathrm{L}_{2}+{ }^{\mathrm{p}} \gamma(\underline{\eta}){ }^{\mathrm{p}} \mathrm{C}\right)
$$

$\underline{\eta}$ is the virtual displacement, $\mathrm{L}_{1}, \mathrm{~L}_{2}$ are the lengths in the warp and weft of the woven cell. ${ }^{\mathrm{p}} \mathrm{A}$ means that quantity $\mathrm{A}$ is written for the woven cell $\mathrm{p}$. $\mathrm{C}$ is the torque exerted by warp yarns on weft yarns created by in the plan shearing $\gamma \cdot \mathrm{T}^{11}$ and $\mathrm{T}^{22}$ are the tensions in the directions of warp and weft yarns $\mathbf{h}_{1}$ and $\mathbf{h}_{2}$ (Fig. 1). Other rigidities are neglected in particular bending stiffness.

In the different simulation approaches that take shear into account [3][8-12][26][4], it is assumed that the shear stress only depends on the warp weft angle $\gamma$ It is an assumption by default, because the large number of experimental work concerning the shear behaviour measurement provides only the shear load according to the shear angle $\gamma[142]$.

In this work a new experimental device is implemented which makes it possible to measure the tensions in a fabric during a shear test. This device will show that, contrary to the classically used assumptions, the shear stiffness varies with the tensions. In addition it will be seen that the classical "picture frame" test used as pure shear test causes tensions in the yarns of the fabric. The tests presented in the present paper are carried out on two composite woven reinforcements: a Twintex plain weave (Fig. 2) composed of glass fibres (60\%) and polypropylene fibres (40\%) $\left(743 \mathrm{~g} / \mathrm{m}^{2}\right)$ and a G1151 fabric $\left(630 \mathrm{~g} / \mathrm{m}^{2}\right)$ where an interlock weaving links two carbon plies (Fig. 
3). The Twintex plain weave fabric will be called 'Plain Weave' and the G1151 fabric will be called 'Interlock' afterwards.

\section{3 - Standard tests for the in plane shear of textile composite preforms}

The experimental analysis of in plane shear behaviour of textle performs has been the subject of many works probably because it is the principal deformation mode of these woven fabrics. [1324]. Two principal devices are used: the hinged framework or "picture frame" and the tensile test at $45^{\circ}$ or "bias test".

Remark: It was shown that the results to shear tests are modified when the test is repeated on the same specimen and that some cycles are necessary before obtaining a stabilized value. Nevertheless, since it is the behaviour during forming which interests us, we will always consider the first cycle of loading in present work, as it is the case in a forming process.

\subsection{Picture frame test}

In this test (Fig. 4), a hinged frame with four bars with equal length is assembled in a tensile testing machine. A tensile force is applied across diagonally opposing corners of the picture frame rig causing the picture frame to move from an initially square configuration into a rhomboid. Consequently, le specimen within the picture frame is theoretically subjected to a pure shear strain field.

In order to compare the results obtained by this test with other results which quantify the shear stiffness, either obtained with different systems, or obtained on different fabrics, the total effort $\mathrm{F}_{\mathrm{C}}$ on the framework is not sufficient. It is necessary to define a quantity characteristic of shear behaviour, independent of the measurement device, and that allows to compare two fabrics and the measures obtained by two laboratories on the same fabric. The torque $\mathrm{C}$ on the unit woven cell as used in the equation (1) is a possible quantity provided that it is made independent of the size of the unit woven cell in order to compare two different fabric, i.e., by noting ${ }^{\mathrm{P}} \mathrm{S}$ the surface of the woven unit cell p: 


$$
\mathrm{C}_{\mathrm{u}}=\frac{\mathrm{C}}{{ }_{\mathrm{p}} \mathrm{S}}
$$

In [20] and [21], the load on the picture frame $F_{c}$ is normalized by :

$$
F_{\text {norm }}=\frac{F_{c} L_{\text {frame }}}{L_{\text {fab }}^{2}}
$$

where $\mathrm{L}_{\text {frame }}$ and $\mathrm{L}_{\text {fab }}$ are the lenghts of the side of the picture frame and of the sample respectively. Equation (3) defines the effort on an element with a unit side. Then the shear load is defined by (Fig. 5):

$$
\mathrm{F}_{\mathrm{sh}}=\frac{\mathrm{F}_{\text {norm }}}{2 \cos (\alpha / 2)}
$$

\& $\pi 2-\gamma$ is the angle between the two bars connected at of top of the picture frame. It is easily shown that

$$
\mathrm{C}_{\mathrm{u}}=\mathrm{F}_{\mathrm{sh}} \cos \gamma
$$

In the present work, $\mathrm{F}_{\mathrm{sh}}$ will be used, to give the results of the different tests. The results of the picture frame shear test show an increase in the shear load with the shear angle and an increase in shear rigidity when the angle becomes large (Fig. 6 for the Plain Weave fabric). This stiffness increase can be sudden for certain woven reinforcements. The corresponding angle is then called shear locking angle.

For the small angles the warp and weft yarns rotate relatively, each yarn having a solid body motion. This has been shown by an optical analysis of the displacements field at the mesoscopic scale i.e. at the scale of the woven yarns $[28,29]$. Fig. 6 shows that the relative displacement field inside a yarn is a rotation field. Strains in the yarn are negligible. The shear load is mainly due to friction between the warp and weft yarns. The locking angle corresponds to the angle from which the geometry of the weaving does not allow any more this rotation and consequently the yarns are subjected to side contacts with other yarns. The relative displacement field inside a yarn shows that the yarn is in lateral compression and this compression is more important as the shear increases (Fig. 6). The shear load is mainly due to this lateral compression in this phase. For 
some weavings and especially for complex "interlock" weavings there is no clear locking angle and the stiffness increase is progressive. The rigidity increase in the second part of the curve is a significant feature because it can involve the formation of wrinkles what one seeks to avoid in a forming process.

The picture frame test presents a main difficulty. The yarns are parallel to the frame sides in order to be not stretched during the test. This is essential because the tension stiffness of the fabric is very large in comparison with the shear one. In practice this alignment is very difficult to achieve initially and during the test for all the yarns. In addition some initial tension is usually applied to the fabric. Its value is generally unknown and its consequences are ignored. This aspect is probably one of the elements that explain the discrepancy between the results obtained to the experimental "benchmark" on shearing [21]. Seven laboratories of five different nationalities have performed picture frame tests on the same woven reinforcement. This fabric has been presented as the Plain Weave fabric in section 2. The obtained shear curves (standardized to make the comparison possible) vary in a very significant ratio. This shows that this experimental shear test is not completely controlled. The objective of the present work is to show that the absence of knowledge of the tensions in this test is a significant problem.

\subsection{Bias test}

An alternative to the picture frame test framework for the measurement of in plane shear behaviour of composite textile preforms consists in a tensile test at $45^{\circ}$ or "bias test" $[16][30,31][17-19][21][23,24]$. In this experiment, a tensile test is performed on a rectangular specimen such that the warp and weft directions of the tows are orientated initially at $\pm 45^{\circ}$ to the direction of the applied tensile load (Fig. 7). When the specimen is stretched from L to L+d (Fig. 8), the fibrous and woven nature of the specimen leads to the following deformed state:

- In zone A, the warp and weft yarns have both a clamped end and there is no deformation in this zone. 
- In zone $\mathrm{C}$, the warp and weft yarns have free ends, the non-sliding at crossovers and the stretching of the specimen leads to a pure shear deformation related to d:

$$
\gamma=\frac{\pi}{2}-2 \operatorname{Arccos}\left(\frac{D+d}{\sqrt{2} D}\right)
$$

- In zone B one yarn direction is clamped at its end, the other direction is free. The stretching of the specimen leads to a shear strain of a value half of that of the zone C.

This test thus makes it possible to have a zone $\mathrm{C}$ in pure shear strain. The first advantage of this test with respect to the picture frame lies in its simplicity of implementation. In addition the yarns of the central zone in pure shear are free at their ends. Consequently they are not in tension. The nature of the test thus leads more naturally to a shear state without tension than the picture frame test. Conversely the intermediate zones B make the test analysis more delicate because the measurement of effort on the machine is global and concerns the deformation of all zones at the same time. The second difficult point in this test concerns the verification of the kinematic assumptions. It is assumed that during the deformation of the woven reinforcement, there is no translation sliding between the warp and weft yarns. Optical analyses show that this is not completely true and that there is a small difference between the theoretical shear given by equation (6) and the measured value when the shear angle becomes large.

Equation (6) relates the shear angle $\gamma$ to the global extension $d$ of the specimen. From the power developed by the tensile machine, the following expression is obtained for the shear load $\mathrm{F}_{\mathrm{sh}}$

$$
\mathrm{F}_{\mathrm{sh}}(\gamma)=\frac{\mathrm{F}_{\mathrm{c}}}{\cos \gamma}\left(\cos \left(\frac{\gamma}{2}\right)-\sin \left(\frac{\gamma}{2}\right)\right)-\mathrm{F}_{\mathrm{sh}}\left(\frac{\gamma}{2}\right)
$$

\subsection{Comparison of the two tests}

The results obtained for the two woven reinforcements presented in section 2 from the picture frame test and by the bias tests are compared. The repeatability of these tests is fairly good taking into account the difficulties involved by these tests. The main scatter can come from the 
manufacturing of the sample. If samples are very carefully manufactured the scatter is usually les than $15 \%$.

Fig. 9 and Fig. 10 show, for the two tests, results appreciably different for the standardized shear load $\mathrm{F}_{\mathrm{sh}}($ Eq. (4)) according to the shear angle $\gamma$. In the next sections of this paper, it will be shown that the spurious tensions present during the picture frame test can be an explanation for these differences.

\section{4 - An experimental device for the tension measurement during shearing}

The significant difference between the response to the picture frame test and to the bias test can be explained by the boundary conditions on the fabric. In the first case the yarns are clamped on the rigid bars of the framework whereas for the bias test they are free. It is supposed that taking into account the geometry and kinematics of the picture frame the tensions remain small during the test. This aspect is questionable especially because tensile stiffness of fabrics is high, thus, a small tensile strain of the yarns leads to significant strain energies and tension in the yarn. This can alter the shear measurement since the tensile rigidity is much larger than the shear one. An other point concerns the assumption made in most experimental and simulation works that consists in assuming that the effort $\mathrm{F}_{\mathrm{sh}}$ (or the in plane shear stress) only depends on the shear angle $\gamma$

In order to measure the warp and weft tensions during a picture frame test and to analyse the consequences of these tensions on the shear stiffness, a specific device is proposed. Devices for measurement and adjustment of the tension are added to a picture frame in the warp and weft directions. (Fig. 11 and 12). In each direction the yarns are fixed on a system which is connected to the picture frame by a load sensor on one end and by an adjustment on the other end. So it is possible to measure the warp and weft tensions during the test and to adjust the initial tensions. Possibly, by stopping the test, warp and weft tensions can be set to given values. The shear angle can be calculated from the frame displacement or be measured by optics measurements. The 
theoretical shear angle $\gamma($ Fig. 13) is related to the extension of the diagonal of the framework d, by:

$$
\gamma=\frac{\pi}{2}-2 \cos ^{-1}\left(\frac{\sqrt{2} \mathrm{~L}+\mathrm{d}}{2 \mathrm{~L}}\right)
$$

It was shown $[28,29]$ that the values of angle obtained by optical measurements are slightly higher because of the clamping at the end of the yarns. This point will not be studied here. The values of angles provided in the present work will be the average values measured by optical measures in the useful zone of the specimen.

It can be shown that a load on a bar of the picture frame in the direction of the adjacent one does not modify the value the load measured on the tensile machine (see appendix A). It is a significant point to analyze the influence of the tensions on shear rigidity: if the yarns are strictly parallel to the picture frame, the tension can modify their in plane shear behaviour but does not directly change the load $\mathrm{F}_{\mathrm{c}}$ on the tensile machine.

The load sensors added on the frame measure the load at right angles to the rigid bar. The yarns do not remain perpendicular to the bars during the test (Fig. 14). It is thus necessary to correct the values measured by the sensors to obtain the tensions in the yarns. The tension in the yarn is obtained from the measure of the sensor by:

$$
\mathrm{T}_{\mathrm{yarn}}=\frac{\mathrm{F}_{\text {sensor }}}{\cos (\gamma)}
$$

This device will first enable to analyze the influence of initial tensions on the shear rigidity of a woven reinforcement. Then, in the second time, the evolution of the tension will be analyzed during a shear test. Finally, tests for which the tensions will be set to zero during the all tests will be performed.

\section{Influence of the initial tension on shear stiffness.}

Shear tests are carried out on the Plain Weave fabric (presented in section 2) using the device presented in section 4 prescribing initial tensions in warp and weft directions. A practical 
difficulty in this test resides in the need for the strict positioning of yarn clampings on the straight line that joins to articulations of the frame. If the ends of the yarns are not clamped on this straight line, the kinematics imposed to the specimen does not correspond to pure shear, the yarns are stretched and are thus subjected to spurious tensions. It is necessary to scrupulously respect this alignment. Even though we can not expect a perfect sample, samples have to be very carefully manufactured. Cameras are used to verify the good alignment of the clamping and the good alignment of the yarns with the frame arms.

Fig. 15 shows the shear loads obtained in the case of the Plain Weave fabric for initial tensions equal to 0,10 and $20 \mathrm{~N}$ per yarn. These results show that the shear load is increased by the tension in the yarns especially in the first part of the shear curve (small and medium shear angles). For a $25^{\circ}$ shear angle, the ratio between the shear load of a test without initial tension and with an initial tension equal to $20 \mathrm{~N}$ is close to 2 . This result is not surprising because the shear rigidity is for a part due to frictions between the yarns (especially in the first part of the curve). When increasing the tension in the yarns, the weaving brings a transverse compressive force and consequently the friction loads and consequently the shear stiffness increases. For large shear angles, the shear load is less affected by the initial tensions. The initial tensions are applied for a null shear angle and their influence on the tension state after a large shear is less important.

\section{Measure of the tension during the shear test}

The second experiment,-that the device described in section 4, makes possible, consists in measuring the yarn tensions in warp and weft directions during a shear test (Fig. 16 to 19). The initial tensions are null. But although the yarn tensions are null at the beginning of the test, they increase in a significant way during the test. Such a picture frame shear test is thus not strictly a pure shear test since fairly important yarn tensions are superimposed. A possible explanation for theses tensions can be found in the geometry on a mesoscopic scale (i.e. the scale of the unit woven cell) and in the woven nature of the reinforcement. It can be noted that the tension in the 
yarns remains null in the first part of the shear test (Fig. 16 and 17). This is reasonable since it as been shown in section 3.1 (Fig 6) that, in the first part of the shear test, the yarns undergo a rigid body rotation and are not in contact with their neighbours. The tension in the yarns only increases significantly from the beginning of the side contacts. When this contact occurs, and since each yarn is not hinged on the frame, the yarns don't remain strictly parallel to the frame arm. This tends to create in plane undulation of the yarns (especially near the arms). Although the distance from one edge to the other of the picture frame is constant, the yarn length increases slightly. Taking into account the strong tension rigidity of the yarns, it results a tension in the yarns. This phenomenon is marked in the case of the Plain Weave fabric and much less clear for the Interlock fabric (Fig. 18 and 19). Actually the internal complexity of the weaving makes that the contact is more progressive and the first rigid rotation zone of the yarns does not almost exist.

\section{Test with a null tension}

The device presented in section 4 makes it possible to measure the warp and weft tensions and to set a tension. The test carried out in the present section consists to stop the test as soon as the tension increases and to set it to a zero value. Such a test will be close to a picture frame test with tensions equal to zero. Results obtained will be closed to the pure in plane shear behaviour as this behaviour appears in the last term of equation (1). Fig. 20 allows comparing the shear curve obtained in this case (for the Plain Weave fabric) with that obtained with a standard picture frame test i.e. without relaxing the tension during the test. It can be seen that the shear force is much smaller if the tension is set to zero. However it is in this case that the only shear stiffness (without tension) is measured. An interesting aspect is the comparison with the bias test on the same frabric. Fig. 20 shows that the results obtained by setting the tension to zero in the picture frame test are rather close to those obtained by the bias test. Tensions in the bias test are null or very small because the ends of yarns of the sheared zone are free. This test clearly shows the significant consequences of the tensions in a standard picture frame test. If a picture frame is used 
to define the pure shear behaviour of a fabric the effect of these spurious tensions has to be zero, at least, as small as possible.

The same procedure (setting the tensions to zero during the test) is carried out on the Interlock fabric (Fig. 21). The results are significant. The shear curve obtained from the picture frame setting the tensions to zero is in good agreement with those obtained from the bias test.

\section{Conclusions and prospects}

A new experimental device makes it possible to measure the tensions in the warp and weft directions during a picture frame shear test. The first results show that the tensions which generally are not taken into account play a significant role in shear beahaviour. When the initial tensions vary, the obtained shear loads in the first part of the test increase with the initial tension. The measurement of the tensions during a picture frame shear test shows that those tensions do not remain null during the test. Finally the relaxation to zero of the tensions during the test significantly decreases the obtained shear load curves and leads to results close to those obtained by the bias test. The experimental results in the present work confirm the shear/tension coupling highlighted by the mesoscopic modelling performed in [26].

The results presented in the present paper are first results which undoubtedly require to be refined and extended to other materials. In particular it seems that concerning prepreg fabrics the presence of resin modifies the internal phenomena [23]. Present finite elements computations suppose that the in plane shear strain energy does not depend on the tension state. In the case of handmade draping processes, the tensions remain small and this assumption is probably sufficient. But when the forming processes uses tools, especially blank holders, the tensions become significant and play a role in the wrinkle formation by modifying the shear stiffness. A next step will be to include in a sufficiently simple way the influence of the tensions on the in plan shear behaviour in textile perform forming simulations. 


\section{Acknowledgement}

The authors acknowledge the support of the ITOOL European project.

\section{Appendix A. Loads on the picture frame}

A loading on the picture frame is considered as shown on Fig. 22. Two opposite loads $\underline{T}$ are applied in $\mathrm{A}$ and $\mathrm{B}$, two points of the bars $\mathrm{KI}$ and $\mathrm{JL}$. The loads $\underline{\mathrm{T}}$ are in the $\mathrm{AB}$ direction. $\mathrm{AB}$ is parallel to the bars IL and JI. The loads $\underline{T}$ are in the theoretical direction of the yarns in the picture frame experiment and can be seen as tensions in the yarns. $\underline{F}_{c}$ is the load on tensile machine that balances the tension $\underline{\mathrm{T}}$.

Considering the equilibrium of the bar IL, the momentum equations in I imposes that the load $\underline{F}_{\mathrm{JL}}$ from JL on LI is in the LI direction. Similarly the load $\underline{\mathrm{F}}_{\mathrm{IK}}$ from IK on KI is in the KJ direction.

The equilibrium of the two bars KIL is studied in Fig. 23 taking the previous remarks into account. If the loads on KIL are projected on KI direction, all the projections are null except those of $\underline{F}_{c}$. Consequently $\underline{F}_{c}$ is equal to zero.

A tension in the theoretical yarn direction does not change the load on the tensile machine by itself. If it modifies the measured load, it is because it modifies the shear rigidity, but not because of it action on the frame equilibrium. Of course if the yarn is not parallel to the side of the picture frame, this is nor more true.

\section{References}

[1] Van Der Ween F. ,'Algorithms for draping fabrics on doubly curved surfaces', International Journal of Numerical Method in Engineering, (1991), 31, 1414-1426.

[2] Trochu F., Gauvin R., Gao D.-M., 'Numerical Analysis of The Resin Transfer Molding Process By The Finite Element Method', Advances in Polymer Technology, (1993), 12 (4), 329-342

[3] Pickett A.K., Queckbörner T., De Luca P. and Haug E., An explicit finite element solution for the forming prediction of continuous fibre-reinforced thermoplastic sheets, Composites manufacturing, (1995), 6, (3-4), 237-243 
[4] Boisse P., 'Finite element analysis of composite forming', Composite forming technologies, Chapter 3, A.C. Long editor, Woodhead Publishing, (2007), 46-79

[5] Mark C., Taylor H. M., 'The fitting of woven cloth to surfaces', Journal of Textile Institute, (1956), 47, 477-488

[6] Long A.C., Rudd C.D., 'A simulation of reinforcement deformation during the production of preform for liquid moulding processes', I. Mech. E. J. Eng. Manuf., (1994), 208, 269278.

[7] Cherouat A., Billoët J.L., Mechanical and numerical modelling of composite manufacturing processes deep-drawing and laying-up of thin pre-impregnated woven fabrics, J. Mat. Proc. Technology, (2001), 118, 460-471.

[8] L. Dong, c. Lekakou and m. G. Bader, Processing of Composites: Simulations of

the Draping of Fabrics with Updated Material Behaviour Law, Journal of Composite Materials, 2001, 35, (2), 138-163

[9] Yu W.R., Pourboghrat F., Chung K., Zamploni M. and Kang T.J., 'Non-orthogonal Constitutive Equation for Woven Fabric Reinforced Thermoplastic Composites', Composites Part A, (2002), 33, 1095-1105

[10] Xue P., Peng X., and Cao J., 'A Non-orthogonal Constitutive Model for Characterizing Woven Composites', Composites Part A, (2003), 34, 183-193

[11] P.Boisse, Zouari B., Gasser A., 'A mesoscopic approach for the simulation of woven fibre composite forming', Composites Science and Technology, (2005), 65, 429-436

[12] Peng X., Cao J., A continuum mechanics-based non-orthogonal constitutive model for woven composite fabrics, Composites: Part A, (2005), 36 859-874

[13] Kawabata S., Niwa M., and Kawai H. The Finite Deformation Theory of Plain Weave Fabrics Part I: The Part III: The Shear Deformation Theory, J. Textile Inst., (1973), 64,1, 62-85.

[14] Prodromou, A.G. and J. Chen, On the relationship between shear angle and wrinkling of textile composite preforms. Composites Part A, (1997), 28, (5), 491-503.

[15] G. B. McGuinness, C. M. O. Bradaigh, Characterisation of thermoplastic composite melts in rhombus-shear: the picture-frame experiment, Composites Part A, (1998), 29,1-2, 115-132.

[16] Wang J, Page JR, Paton R. Experimental investigation of the draping properties of reinforcement fabrics. Composites Science and Technology, (1998), 58, 229-237.

[17] Potter K. Bias extension measurements on cross-plied unidirectional prepreg. Composites Part A (2002), 33, 63-73.

[18] Gilbert Lebrun, Martin N. Bureau, Johanne Denault, Evaluation of bias-extension and picture-frame test methods for the measurement of intraply shear properties of PP/glass commingled fabrics, Composite Structures, (2003), 61, 341-352

[19] Sharma SB, Sutcliffe MPF. A simplified finite element model for draping of woven material. Composites Part A, (2004), 35, 647-53.

[20] X.Q. Peng, J. Cao, J. Chen, P. Xue, D.S. Lussier, L. Liu, Experimental and numerical analysis on normalization of picture frame tests for composite materials, Composites Science and Technology, (2004), 64, 11-21 
[21] Cao J., Cheng H. S., Yu,T. X., Zhu B., Tao X. M., Lomov S. V., Stoilova Tz, Verpoest I., Boisse P., Launay J., Hivet G., Liu L., Chen J., De Graaf E. F., Akkerman R., 'A cooperative benchmark effort on testing of woven composites', Proceedings of the 7th Int. ESAFORM conference on Material Forming, Trondheim, Norway, (2004), 305-308

[22] S.V. Lomov, Tz.Stoilova, I.Verpoest, Shear of woven fabrics: theoretical model, Numerical experiments and full field strain measurements, Proceedings of the $7^{\text {th }}$ Int. ESAFORM conference on Material Forming, Trondheim Norway, (2004), 345-348

[23] Harrison P, Clifford MJ, Long AC. Shear characterisation of viscous woven textile composites: a comparison between picture frame and bias extension experiments. Composites Science and Technology, (2004), 64, 1453-65.

[24] P. Potluri, D.A. Perez Ciurezu, R.B. Ramgulam, Measurement of meso-scale shear deformations for modelling textile composites, Composites Part A, (2006), 37, 303-314

[25] Lomov SV, Truong Chi T, Verpoest I, Peeters T, Roose V, Boisse P,et al. Mathematical modelling of internal geometry and deformability of woven preforms. Int J Forming Processes, (2003), 6 (3-4), 413-42.

[26] S.V. Lomov , I. Verpoest, Model of shear of woven fabric and parametric description of shear resistance of glass woven reinforcements, Composites Science and Technology, (2006), 66, 919-933

[27] Boisse P., Zouari B., Daniel J.L., "Importance of In-Plane Shear Rigidity in Finite Element Analyses of Woven Fabric Composite Preforming », Composites A. (2006), 37, (12), 2201-2212.

[28] Dumont F.,'Contribution à l'expérimentation et à la modélisation du comportement mécanique de renforts de composites tissés', Ph.D. Thesis, Université Paris 6, (2003).

[29] F. Dumont, G. Hivet, R. Rotinat, J. Launay, P. Boisse, P.Vacher, Identification des caractéristiques mécaniques de renforts tissés à partir de mesures de déformations par corrélation d'images, Mécaniques et Industries, (2003), 4, 627-635

[30] J. Page, J. Wang, Prediction of shear force and an analysis of yarn slippage for a plainweave carbon fabric in a bias extension state, Composites Science and Technology, (2000), 60, 977-986

[31] J. Page, J. Wang Prediction of shear force using 3D non-linear FEM analyses for a plain weave carbon fabric in a bias extension state, Finite Elements in Analysis and Design, (2002), 38, 755-764 


\section{Figure caption}

Fig.1. Warp and weft directions of a fabric.

Fig. 2. Twintex ${ }^{\circledR}$ plain weave

Fig. 3. Interlock $\mathrm{G} 1151^{\circledR}$ fabric

Fig. 4. Shear frame device equipped with an optical system

Fig. 5. Normalized load and shear load on a rhomboid with unit side

Fig. 6. In plane shear curve of the Plain Weave Fabric

Fig. 7. Bias test and optical measurement

Fig. 8. Bias test specimen, before and after testing. The zone $\mathrm{C}$ in pure shear

Fig 9. Picture frame and bias test results for the Plain Weave fabric

Fig. 10. Picture frame and bias test results for the Interlock fabric

Fig. 11. Picture frame with tension measurements. Initial state.

Fig. 12. Picture frame with tension measurements. Sheared state

Fig. 13. Pure shear kinematics

Fig. 14. Tensions in the yarns during shear deformation

Fig. 15. Shear load curves for different initial tensions

Fig. 16. Tension in warp direction during a picture frame test on the Plain-Weave fabric

Fig. 17. Tension in weft direction during a picture frame test on the Plain-Weave fabric

Fig.18. Tension in warp direction during a picture frame test on the Interlock fabric

Fig .19. Tension in weft direction during a picture frame test on the Interlock fabric

Figure 20. Picture frame test with tensions equal to zero on the Plain Weave fabric.

Comparison with strandard picture frame and bias test.

Fig. 21. Picture frame test with tensions equal to zero on the Interlock fabric. Comparison with standard picture frame and bias test.

Fig. 22. Picture frame submitted to tensions in the yarn direction.

(a) Loads on the frame, (b) Loads on the upper half 


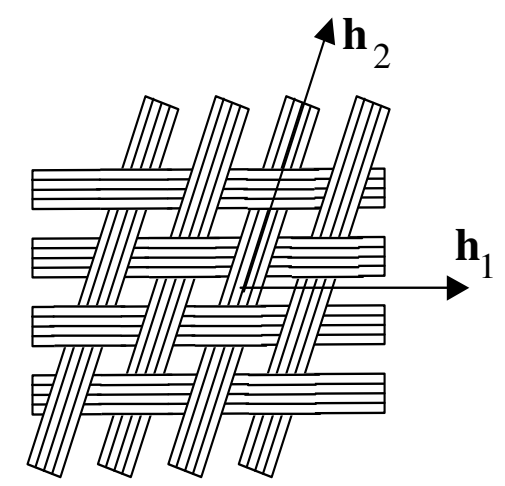

Fig.1. Warp and weft directions of a fabric.

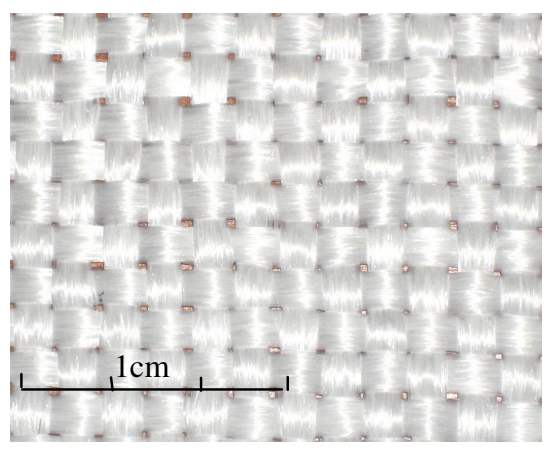

Fig. 2. Twintex ${ }^{\circledast}$ plain weave

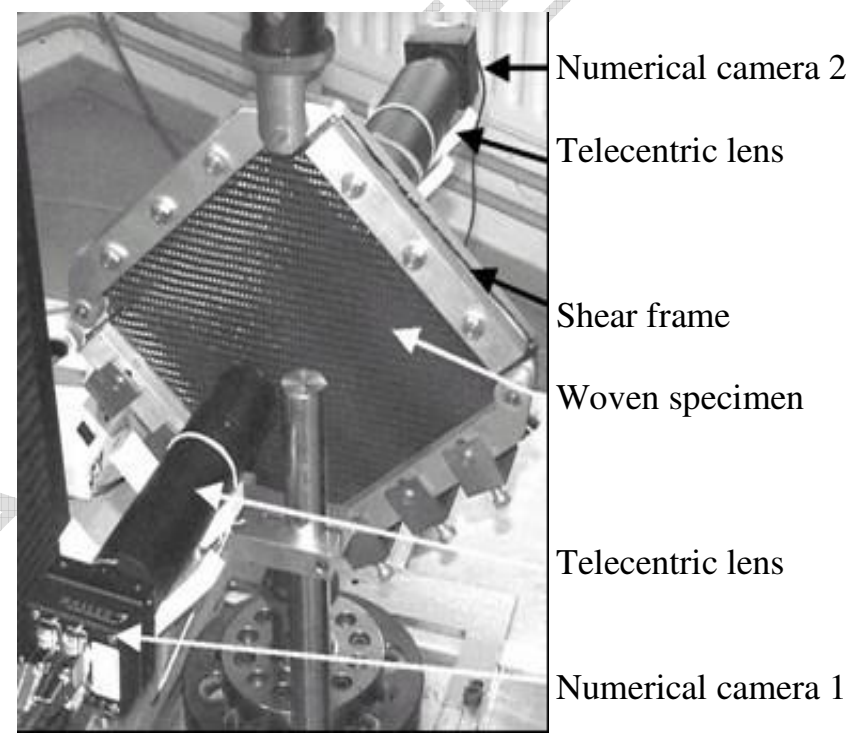

Fig. 4. Shear frame device equipped with an optical system

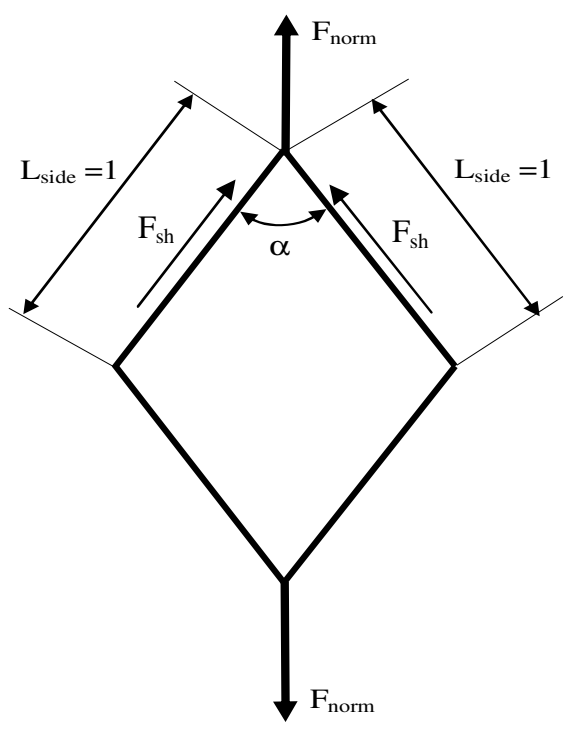

Fig. 5. Normalized load and shear load on a rhomboid with unit side 


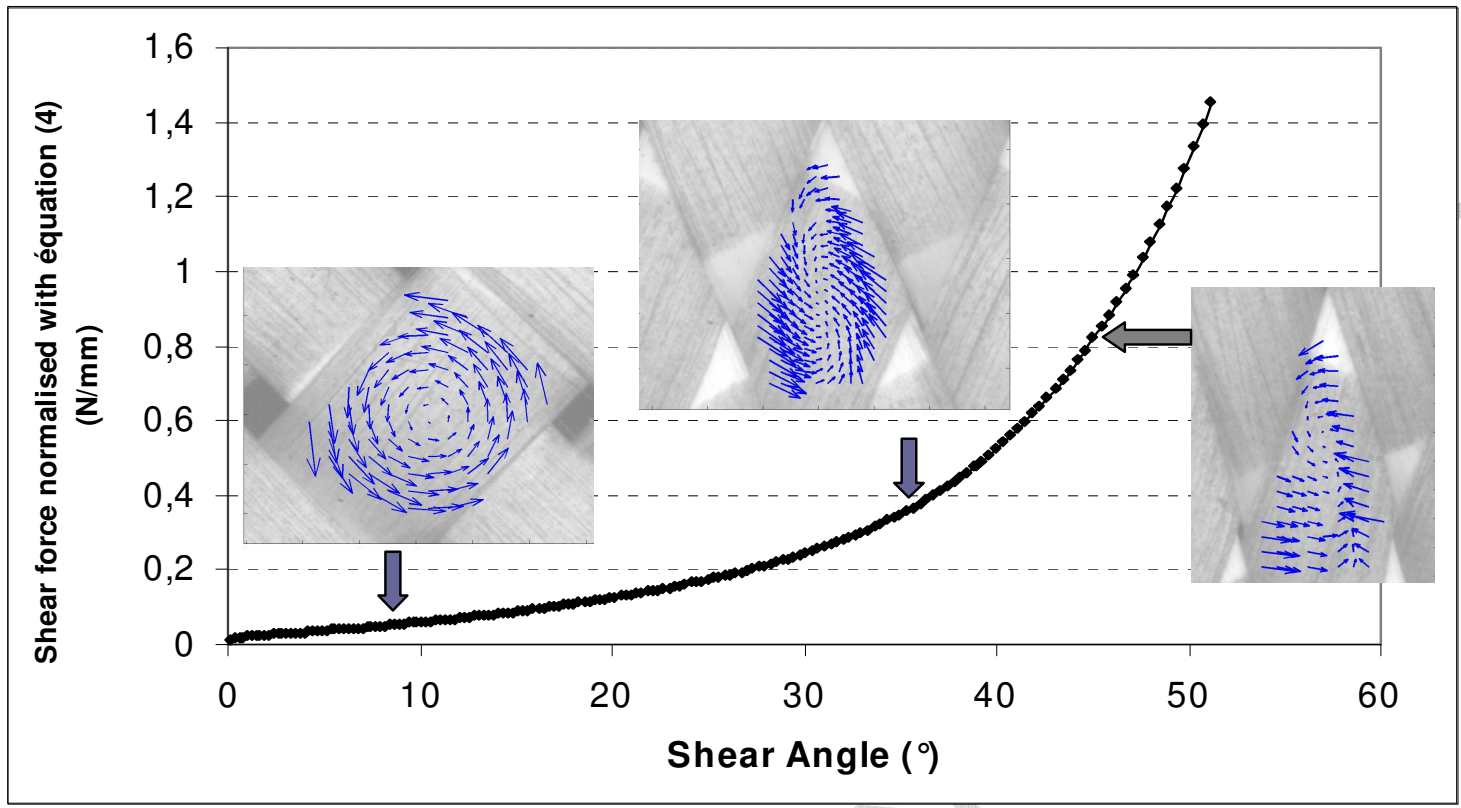

Fig. 6. In plane shear curve of the Plain Weave Fabric

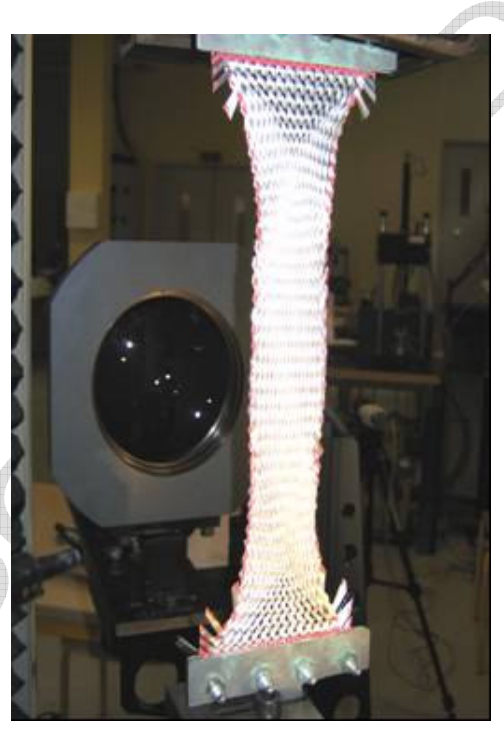

Fig. 7. Bias test and optical measurement

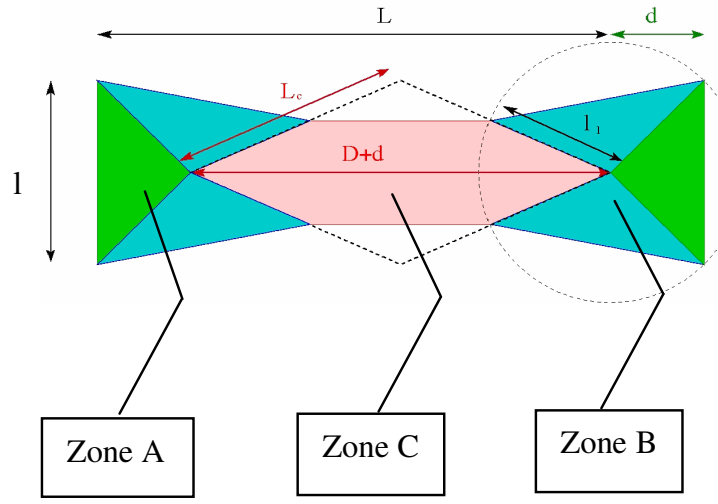

Fig. 8. Bias test specimen, before and after testing. The zone $\mathrm{C}$ in pure shear 


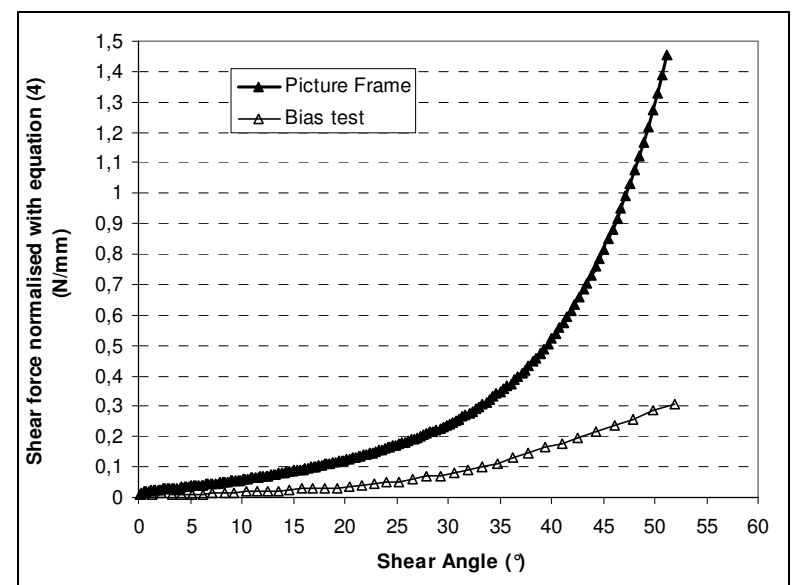

Fig 9. Picture frame and bias test results for the Plain Weave fabric

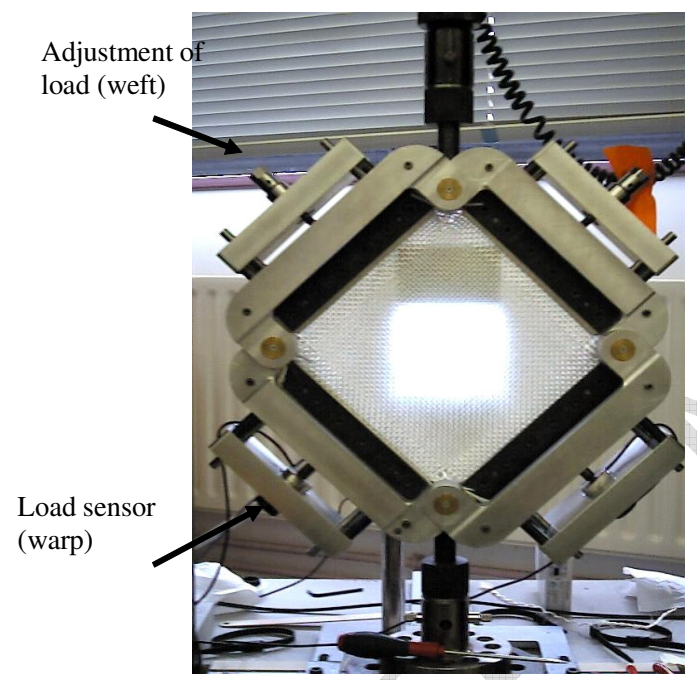

Fig. 11. Picture frame with tension measurements. Initial state.

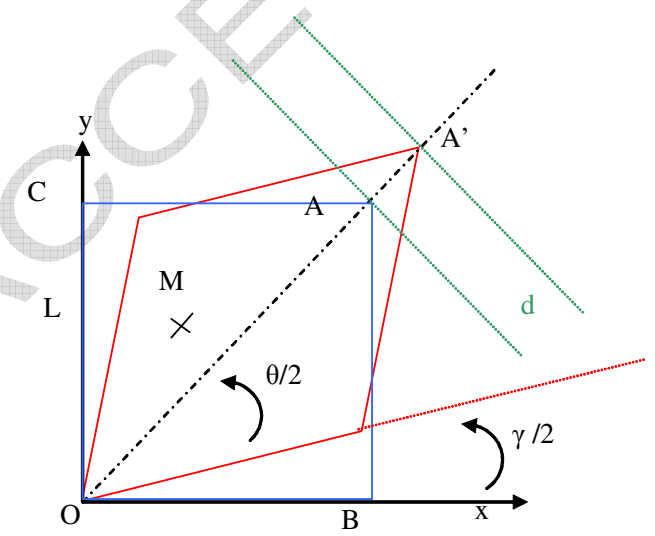

Fig. 13. Pure shear kinematics

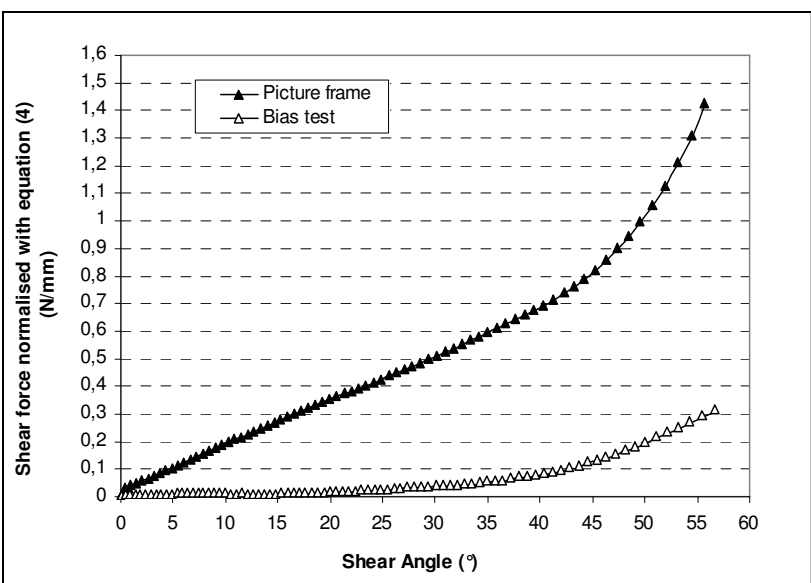

Fig. 10. Picture frame and bias test results for the Interlock fabric

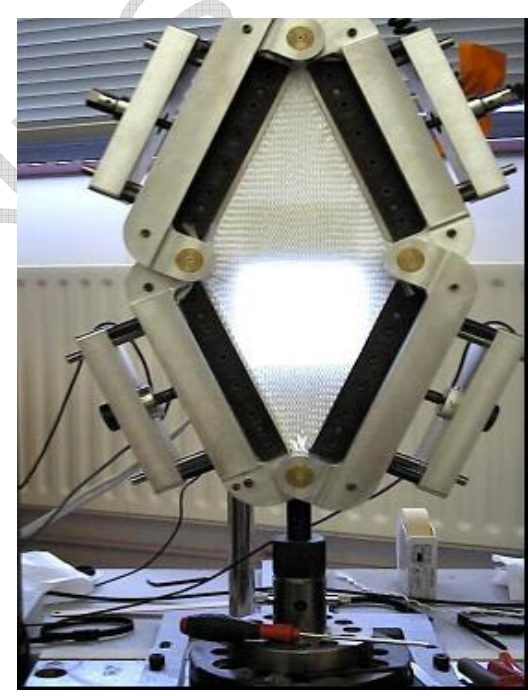

Fig. 12. Picture frame with tension measurements. Sheared state.

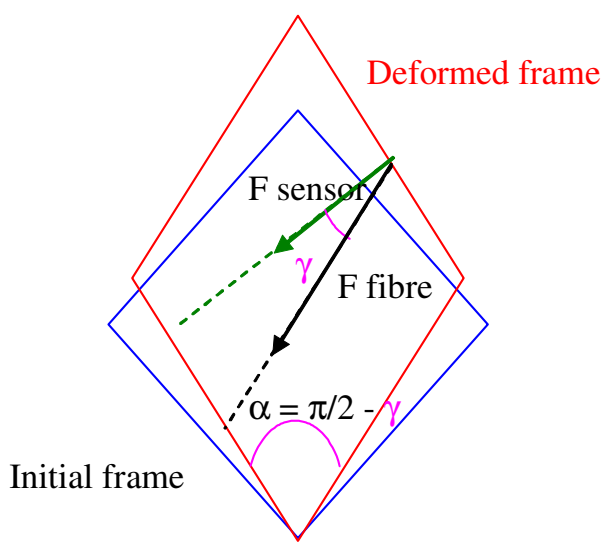

Fig. 14. Tensions in the yarns during shear deformation 


\section{ACCEPTED MANUSCRIPT}

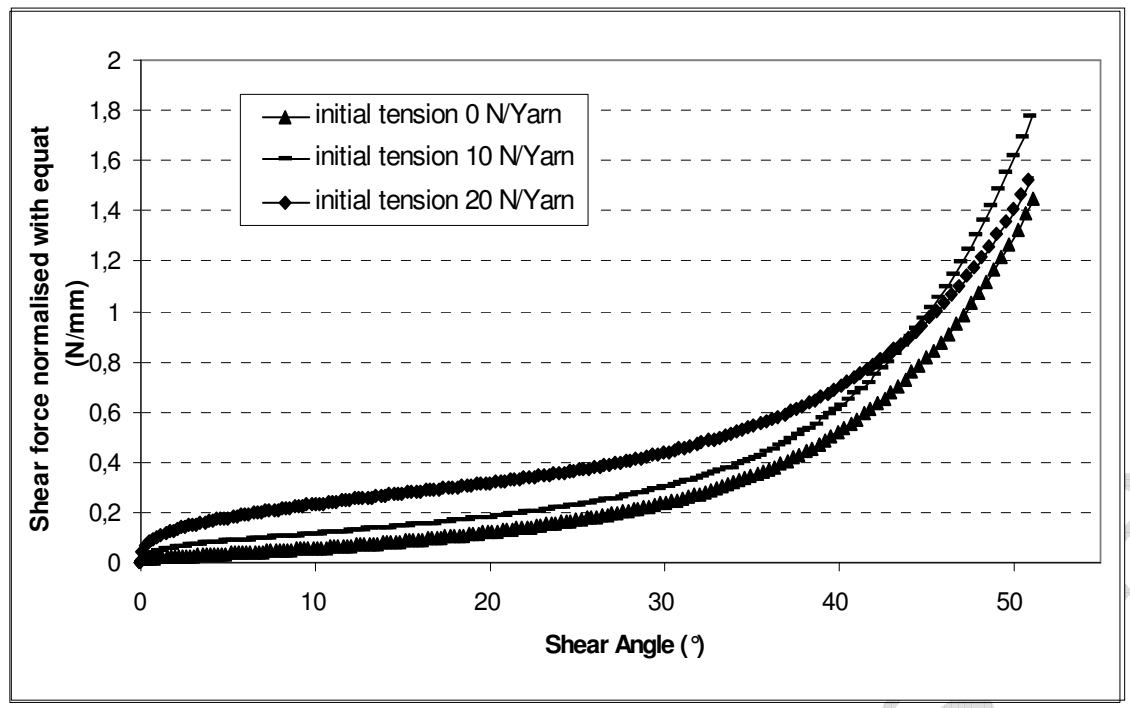

Fig. 15. Shear load curves for different initial tensions

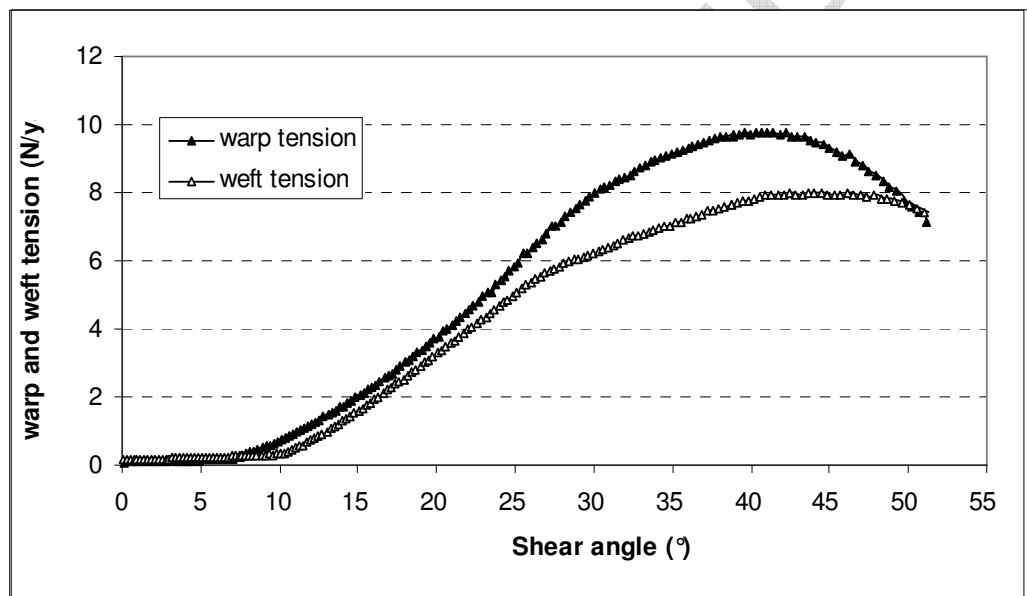

Fig. 16. Tension in warp and weft direction during a picture frame test on the Plain-Weave fabric

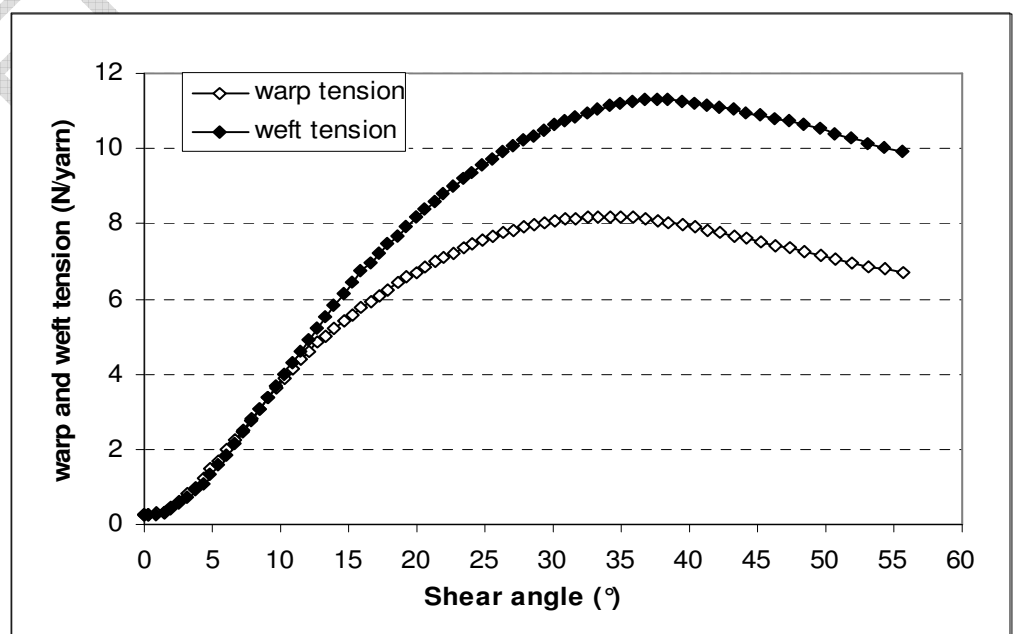

Fig.18. Tension in warp and weft direction during a picture frame test on the Interlock fabric 


\section{ACCEPTED MANUSCRIPT}

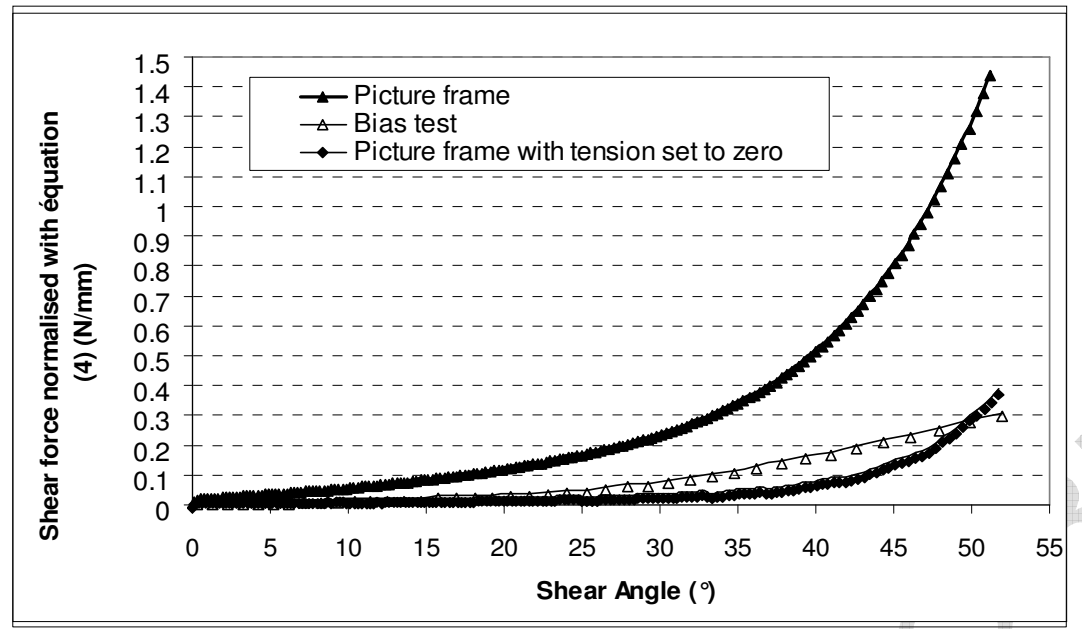

Figure 20. Picture frame test with tensions equal to zero on the Plain Weave fabric. Comparison with standard picture frame and bias test.

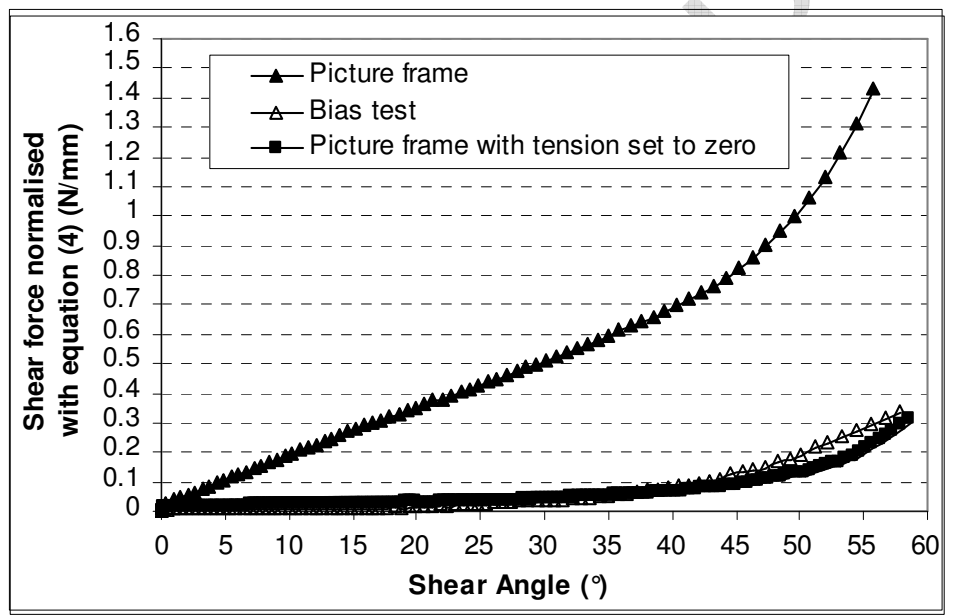

Fig. 21. Picture frame test with tensions equal to zero on the Interlock fabric.

Comparison with standard picture frame and bias test
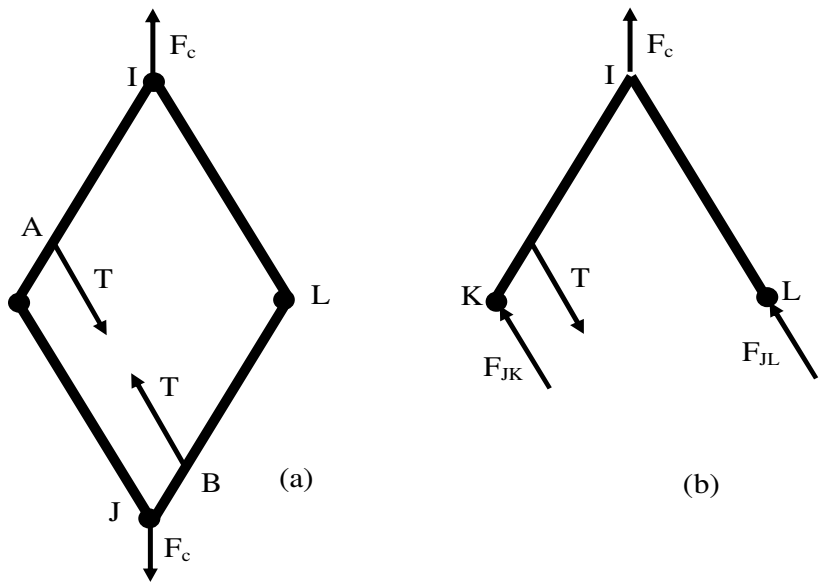

(b)

Fig. 22. Picture frame submitted to tensions in the yarn direction

(a) Loads on the frame, (b) Loads on the upper half 